\title{
EVIDENCE FOR ANAEROBIC DECHLORINATION OF DECHLORANE PLUS IN SEWAGE SLUDGE
}

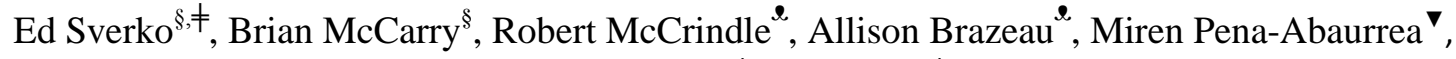 \\ Eric Reiner ${ }^{\boldsymbol{}}$, Shirley Anne Smyth $^{\ddagger}$, Biban Gill ${ }^{\perp}$ and Gregg T. Tomy
}

\footnotetext{
${ }^{\S}$ Department of Chemistry and Chemical Biology, McMaster University, Hamilton, Ontario, L8S 4M1, Canada

${ }_{\text {}}$ Water Science and Technology Directorate, Environment Canada, Burlington, Ontario, L7R 4A6, Canada

${ }^{\perp}$ Department of Biological Sciences, University of Toronto Scarborough Campus, Toronto, Ontario, M1C 1A4, Canada

" Department of Chemistry, University of Manitoba, Winnipeg, Manitoba, R3T 2N2, Canada

\Ministry of the Environment, Toronto, Ontario, M9P 3V6, Canada

'Wellington Laboratories, Guelph, Ontario, N1G 3M5, Canada
}

\section{$\underline{\text { Table of Contents }}$}

Figure S1. Amount of ${ }^{13} \mathrm{C}$-labeled-syn and anti-DP at each sampling point during the 49 day incubation

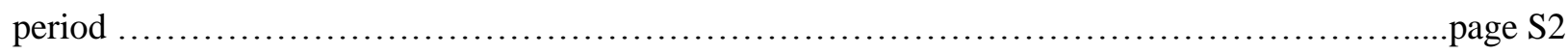

Figure S2. Sewage sludge samples were taken from Niagara on the Lake (NOTL) and Fort Erie sampling sites ..page S3

Table S1. Concentrations of syn and anti-DP along with dechlorination products found in three sediment samples .... .page S4 


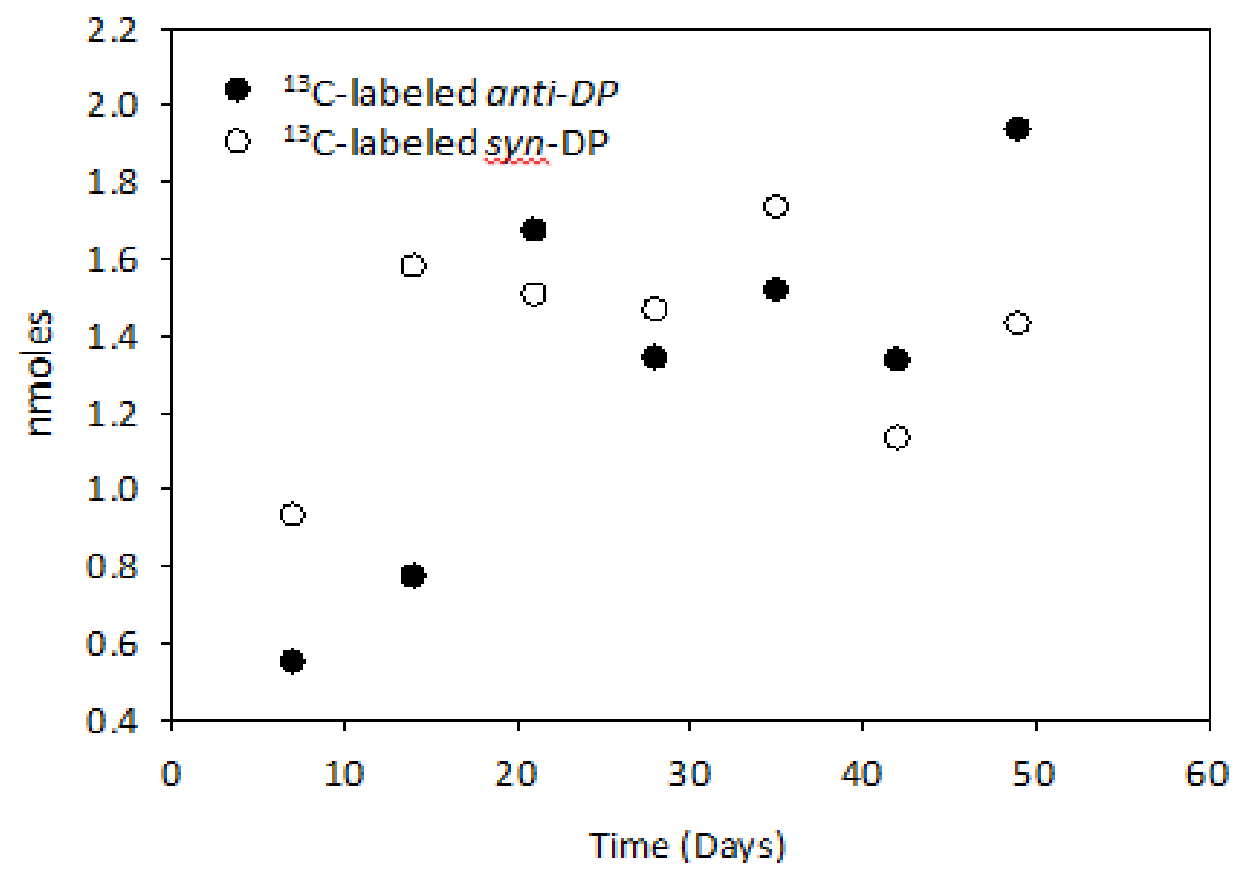

Figure S1. Amount of ${ }^{13} \mathrm{C}$-labeled-syn and anti-DP at each sampling point during the 49 day incubation period 


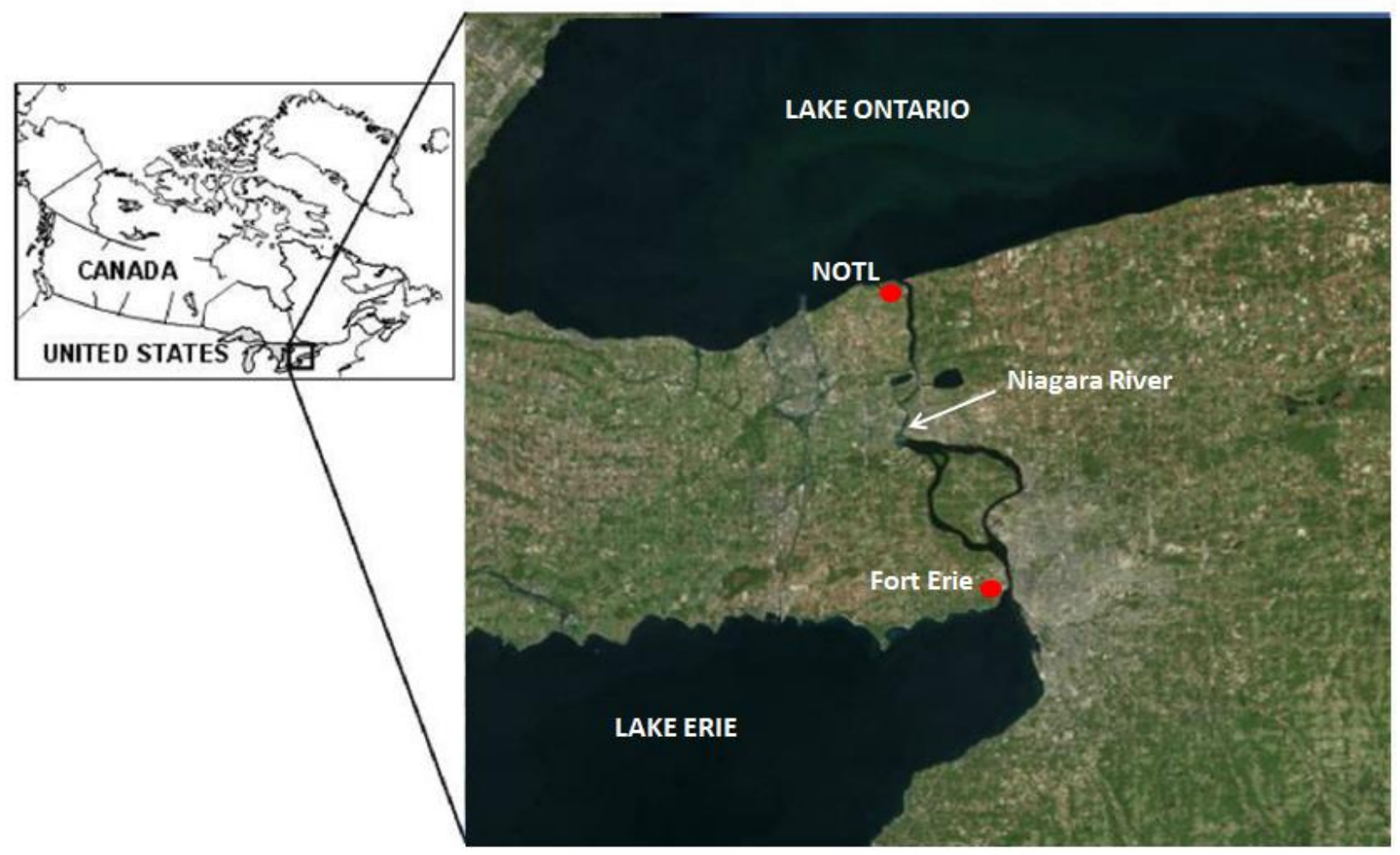

Figure S2. Sewage sludge samples were taken from Niagara on the Lake (NOTL) and Fort Erie sampling sites 
Table S1. Concentrations of syn and anti-DP along with dechlorination products found in three sediment samples

\begin{tabular}{|c|c|c|c|}
\hline \multicolumn{4}{|c|}{ ng/g } \\
\hline Syn-DP & Sed 1 & Sed 2 & Sed 3 \\
\hline syn-DP-1Cl $($ exo $)$ & 2.04 & 1.87 & 0.57 \\
\hline anti-DP & 0.83 & 0.44 & 0.046 \\
\hline anti-DP-1Cl (exo) & 3.42 & 6.49 & 0.84 \\
\hline anti-DP-1Cl $($ endo $)$ & 1.67 & 2.00 & 0.070 \\
\hline
\end{tabular}

